\title{
Power Quality Issues of 3MW Direct-Driven PMSG Wind Turbine
}

\author{
Ibrahim. A. Ahmed \\ College of Engineering, Design \\ and Physical Sciences \\ Brunel University London \\ Ibrahim.Ahmed@brunel.ac.uk
}

\author{
Ahmed. F. Zobaa \\ College of Engineering, Design \\ and Physical Sciences \\ Brunel University London \\ Ahmed.Zobaa@brunel.ac.uk
}

\author{
Gareth. A. Taylor \\ College of Engineering, Design \\ and Physical Sciences \\ Brunel University London \\ Gareth.taylor@brunel.ac.uk
}

\begin{abstract}
This paper presents power quality issues of a grid connected wind generation system with a MW-class direct-driven permanent magnet synchronous generator (PMSG). A variable speed wind turbine model was simulated and developed with the simulation tool of PSCAD/EMTDC. The model includes a wind turbine with one mass-model drive train model, a PMSG model and a full-scale voltage source back to back PWM converter. The converter controller model is employed in the dq-synchronous rotating reference frame and applied to both generator and grid sides. To achieve maximum power point tracking, a tip speed ratio method is applied in machine side, whereas DC voltage control is applied in grid side to achieve constant DC voltage. Due to wind fluctuation and power oscillation as a result of wind shear and tower shadow effects (3p), there will be a fluctuation in the output power and voltage. The concerned power quality issues in this work are Harmonics, power fluctuation and flicker emission. The measurements will be carried out under different wind speed and circumstances.
\end{abstract}

Key words: PMSG, Variable Speed Wind Turbine System, Back to Back Converter Control, Power Quality

\section{INTRODUCTION}

Considering the concern around pollution produced by fossil fuels which has adverse effects on climate change and global warming, and because of the expense of oil; attention has been pain to alternative energy sources to contribute to energy production around the world. Renewable energy production has seen a significant increase in recent decades due to the demand for electricity. An effective type of alternative energy is wind power; the capacity of wind energy reached 17351 MW in March 2012[1]. There are different concepts in terms of coupling generators to wind turbine, the most well-known being the fixed and variable speed wind turbine generator concept. The Squirrel cage induction machine fixed speed wind turbine was the conventional concept used in wind energy in the early stages. In it, the generator is connected directly to the utility network, however, the disadvantages of this concept are low efficiency and that transferring the mechanical stress to the network leads to poor power quality. A variable speed wind turbine generator is a preferable replacement for fixed speed, because it displays certain advantages over fixed speed; a wide operating side rectifier which converts AC to DC and can be a diode-bridge or switch-bridge, and a grid-side inverter which converts DC to AC. In addition, a back to back converter with two identical IGBT bridges is a good choice because of its efficiency and performance [2][3].

The existence of power electronics introduces Harmonics to the connected grid as a result of its nonlinear behavior. This was also due to the variation of natural wind speed and $3 \mathrm{P}$ oscillations (wind shear and tower shadow effect); fluctuations occur in output voltage and power, however, voltage fluctuation may cause flicker, which can also be caused by wind system switching operation and load changes [3][4][5].

This paper develops a comprehensive, detailed model of 3MW PMSG variable speed wind turbine system. The system consists of a wind turbine model including an aerodynamic and a mechanical model. Another part of the system is the electrical system and its control structure. The control of the system covers maximum power tracking operating achieved by generator-side control, whereas the independent activereactive power control strategy is achieved by grid-side control. The entire system is implemented using Power System Computer Aided Design (PSCAD/EMTDC) software. The modeled wind power system is connected to the distribution network which consists of an infinite bus, three linear loads, one nonlinear load and a motorised load. The study has demonstrated the impact of the wind turbine system on voltage stability and harmonic distortion.

\section{MODELING OF VARIABLE SPEED PMSG WT}

\section{A. Modeling of Variable Speed PMSG WT}

The principle of wind turbines is to extract the kinetic energy from wind and convert it to mechanical energy, and then transfer it to a generator via a shaft. The generator converts the mechanical energy into electricity. There is an option to place a gearbox between the shaft and generator to increase the rotating speed, and this depends on generator topology. The power delivered by wind turbines can be expressed by Betz low [6][7]: 


$$
\begin{aligned}
& P=\frac{1}{2} \rho \pi r^{2} C p(\lambda, \beta) V^{3} \\
& \lambda=\frac{\omega . \mathrm{r}}{\mathrm{V}} \\
& C p(\lambda, \beta)=0.22\left[\frac{116}{\lambda i}-0.4 \beta-5\right] e^{\frac{-12.5}{\lambda i}} \\
& \frac{1}{\lambda i}=\frac{1}{\lambda+0.08 \beta}-\frac{0.035}{\beta^{3}+1}
\end{aligned}
$$

Where $P$ is the output power from WT in watt, $\rho$ is air density $\left(\mathrm{Kg} / \mathrm{m}^{3}\right), r$ is the WT blade length $(m), C \mathrm{p}(\lambda, \beta)$ is the power coefficient of the turbine, $V$ is the wind speed, $\beta$ is the pitch angle of the blades (degree) and $\lambda$ is the tip speed ratio. The power coefficient is a function of tip-speed-ratio $(\lambda)$ and pitch angle $(\beta)$. In practice, the wind speed varies and so does the rotor speed, so the goal of controller is to keep the power coefficient at its maximum point which occurs at $\lambda=$ 6.33. Figure 1 shows the power coefficient from the wind turbine against its tip speed ratio.

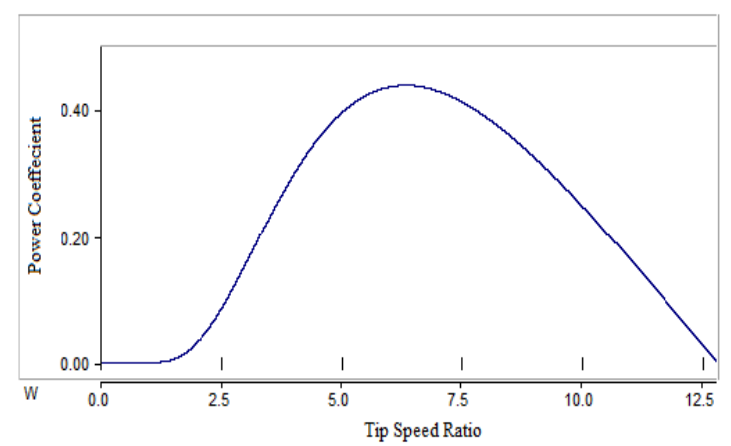

Fig. 1, Power Coefficient of Varying Tip Speed Ratio

\section{B. Modeling of Tower Shadow Effect and Wind Shear}

Wind shear is a variation in the wind with height. During one complete cycle of the wind turbine each blade will experience a minimum wind speed which leads to oscillation in the torque, which in turn contributes to $3 p$ frequency. Also, due to the presence of the tower, the distribution of the wind is altered which affects the blade aligned with the tower. This effect is known as the tower-shadow-effect. For 3-blade wind turbines, every full revolution contains three periodic power pulsations, also known as $3 p$ frequency. Several studies focused on this effect have been conducted [8][9]. The equivalent speed of tower shadow $\left(V_{\text {shadow }}\right)$ and wind shear $\left(V_{\text {sheer }}\right)$ are calculated as the following:

$$
\begin{aligned}
V_{\text {shadow }} & =\frac{\mathrm{m} V}{3 r^{2}} \sum_{b=1}^{3}\left(\frac{a^{2}}{\sin ^{2} \theta_{b}} \ln \left[\frac{r^{2} \sin ^{2} \theta_{b}}{x^{2}}+1\right]-\frac{2 a^{2} r^{2}}{r^{2} \sin ^{2} \theta_{b}+x^{2}}\right) \\
\mathrm{m} & =1+\frac{\alpha(\alpha-1) r^{2}}{8 \mathrm{H}} \\
V_{\text {sheer }} & =V\left(\frac{\alpha(\alpha-1)}{8}\left[\frac{r}{H}\right]^{2}+\frac{\alpha(\alpha-1)(\alpha-2)}{60}\left[\frac{r}{H}\right]^{3} \cos 3 \theta\right)
\end{aligned}
$$

$r=$ blade length, $V=$ wind speed, $a=$ tower radius, $\theta=$ azimuthal angle, $x=$ longitudinal distance from blade to tower centre, $\mathrm{H}=$ rotor hub height and $\alpha=$ wind shear empirical. Figures 2 and 3 show the effects of wind shear and tower shadow on the wind speed. Figures 2 and 3 show the variations of wind due to shear and tower shadow for the proposed system.

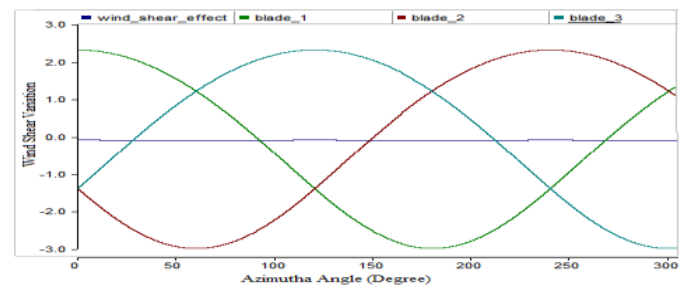

Fig. 2, Wind Shear in the Three Blades of the Wind Turbine at the Hub

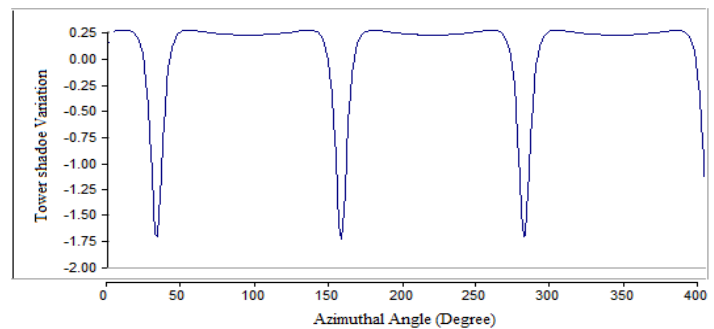

Fig. 3, Tower Shadow Effect for a Three-bladed Wind Turbine.

\section{Wind Turbine Drive Train Model}

The wind turbine drive train system consists of a rotating blade, the shaft and the generator rotor, however, since this paper investigates the power quality, the drive train system can be modeled in one-mass model for simplicity [7]. Its dynamic equation is:

$\frac{d \omega_{m}}{d t}=\frac{1}{J_{m}}\left[T_{m}-T_{e}-B \omega_{m}\right]$

$D$. Where $J_{m}=$ the system total moment of inertia, $T_{m}=$ wind turbine mechanical torque, $T_{e}=$ generator electrical torque and $B=$ rotational damping.

\section{PMSG Model}

Permanent magnet materials provide the excitation which is constant and the PMSG dynamic model is represented by a d-q synchronous reference frame [1][6][7]. PMSG developed by PSCAD/EMTDC has been used in this study. The following equations are based on stator current and voltages:

$$
\begin{aligned}
& v_{s d}=R_{s} i_{d} \frac{d \lambda_{d}}{d t}-\omega_{e} \lambda_{q} \\
& v_{s q}=R_{s} i_{q} \frac{d \lambda_{q}}{d t}+\omega_{e} \lambda_{d}
\end{aligned}
$$

Where $R_{s}$ is stator resistance, $v_{s d}, v_{s q}, i_{d}, i_{q}$ are the stator voltage and current in the $\mathrm{d}-\mathrm{q}$ reference frame and $\lambda_{q}, \lambda_{d}$ are the induced flux linkage in stator $(\mathrm{d}-\mathrm{q})$. Their equations are:

$$
\lambda_{d}=L_{s d} i_{d}+\lambda_{m} \quad \lambda_{q}=L_{s q} i_{q}
$$

Where $L_{s d}$ and $L_{s q}$ are d-q stator winding inductances, $\lambda_{m}$ is magnetic flux. The electromagnetic torque is expressed as the following: 
$T_{e}=\frac{3}{2} n_{p}\left[\lambda_{m} i_{q}-\left(L_{s q}-L_{s d}\right) i_{q} i_{d}\right]$

$n_{p}$ denotes the pole pair number of PMSG. In this work, a surface-mounted PMSG is used where $L_{s q}$ and $L_{s d}$ are almost the same which simplifies the torque equation.

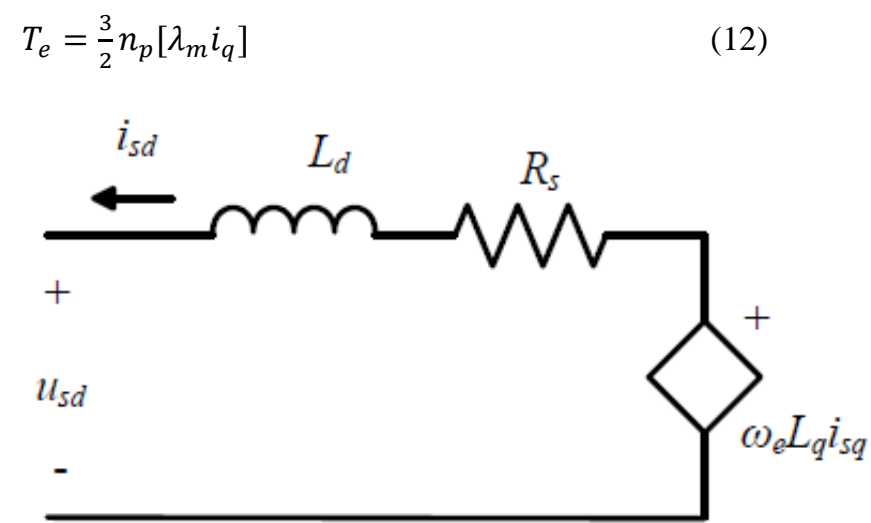

(a)

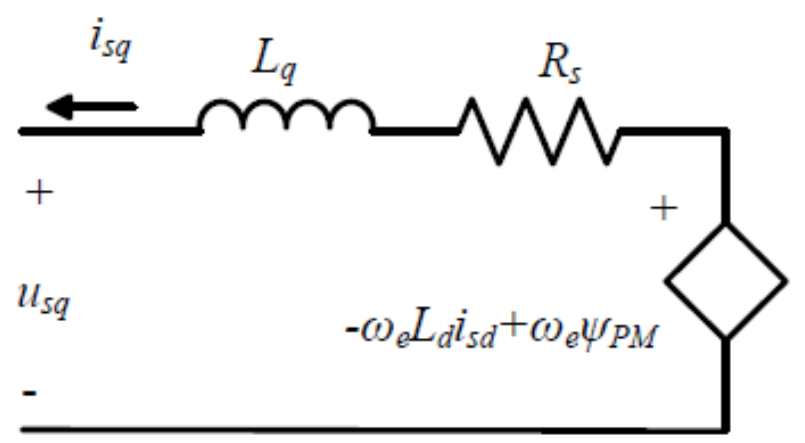

(b)

Fig. 4. Equivalent Circuit of a PMSG in the Synchronous Reference Frame (a) d-axis, (b) q-axis

\section{CONTROL STRATEGY OF THE PROPOSED SYSTEM}

In a variable speed wind turbine system, the controller is required to achieve two aims during wind speed variation. The first of which is to keep the power coefficient at its maximum level below the rated speed, while the other target when the wind speed is higher than desired; the controller keeps the output power is constant. In order to achieve these aims by PMSG, the following two control schemes are realized: speed and pitch control. The speed control is accomplished by the machine side controller described in [6][7], whereas the pitch angle control has been developed in PSCAD/EMTDC and has been used in this paper.

\section{A. Machine Side Control}

The machine side control is designed based on $\mathrm{d}-\mathrm{q}$ parks of the stator currents of the PMSG. The control is accomplished by two independent control loops. Firstly, the stator direct current component $i_{d}$ is adjusted to $i_{d}$ reference which is set to 0 in order to operate the generator at unity power factor [10]. The second control loop consists of two cascade loops (inner and outer); the outer loop controls the rotor speed to extract maximum power by injecting the reference $i_{q}$ to the inner loop, while the reference speed is given by MPPT algorithm which depends on P- $\omega$. Figure (5 illustrates the extracted power under different wind and rotor speeds, and [6][7] describes in detail how to obtain the reference speed. The inner loop (current loop) response has to be faster than the rotor speed loop in order to track the shaft speed. A schematic diagram of machine side control is shown in Figure 6.

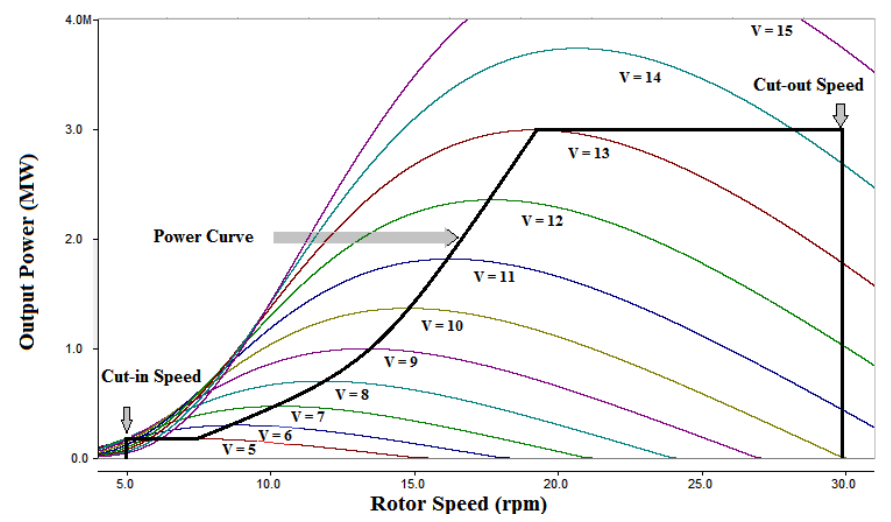

Fig. 5. Power Characteristics of the Wind Turbine Used in this Study for Different Wind Speed

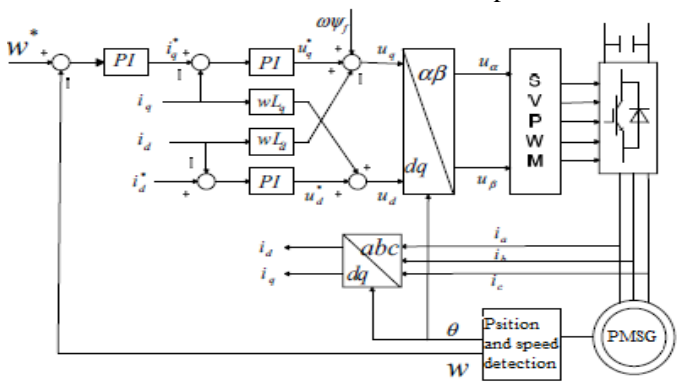

Fig. 6. Control Strategy Scheme for Generator Side Converter

\section{B. Grid Side Converter}

The controller is designed based on the grid currents in the $\mathrm{d}-\mathrm{q}$ reference frame, the controller consists of two control loops. The first loop controls the reactive power where its reference is set to zero to keep the power factor at full unit. The second loop controls the d-component of the grid current and the DC link voltage by two cascade loops. The outer loop determines the reference $i_{d}$ of the grid, whereas the inner loop regulates $i_{d}$ to its reference. The inner loop is designed to be faster than the outer loop in order to follow the variation in the signals [6][7][11]. A phase locked loop is need to 
determine the angular frequency and its design is described in [10] [12].

The grid side model is illustrated in Figure 7.

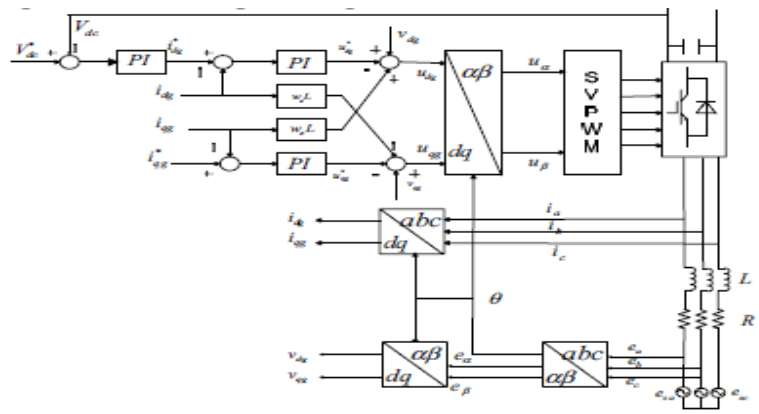

Fig. 7. Control Strategy Scheme for Grid Side Converter

\section{POWER QUALITY ISSUES RELATED WIND TURBINE}

The quality of electric grid voltage is affected by the injection of wind power due to several factors such as power electronics, $3 p$ frequency and wind variations. This effect should not exceed a certain limit in order to comply with utility requirements [3][9][16]. The assessment and measurement procedures for the power quality of wind power were studied by the International Electrotechnical Commission (IEC) and standards were given in IEC 6140021.

IEC 61400-21[16] provides Power Quality Characteristics of different Wind turbine types. This paper considers only those are relevant to variable speed wind turbines which are:

\section{A. Voltage Fluctuations and Flicker}

Natural wind speed varies in amplitude and direction which cause a fluctuation in output power and voltage of the wind turbine. The voltage fluctuation depends on grid phase angle, power factor and power fluctuation. The fluctuation in voltage can be calculated by equation (13) [13]. A rapid voltage change or switching operation causes a sharp voltage fluctuation which leads to a noticeable change in the lighting system and can be detected by the human eye. This is known as Flicker [3][16]. Flicker emission from an individual wind turbine at the PCC is given by (14).

$$
\begin{gathered}
d=100 \% \cdot \frac{\Delta U_{n}}{U_{n}} \\
C\left(\Psi_{k}, V_{a}\right)=P_{s t} \frac{s_{k}}{s_{n}}
\end{gathered}
$$

Where $d$ is Percentile Voltage change, $U_{n}$ is nominal voltage, $C\left(\Psi_{k}, V_{a}\right)$ is Flicker coefficient and it depends on annual wind speed and the grid impedance angle, $P_{s t}$ is short-term flicker emission, $S_{k}$ is the grid short-circuit power at PCC and $S_{n}$ is the apparent power of the wind turbine.

$P_{s t}$ is calculated by a flickermeter designed by IEC 61400-21, [14][15] describe the theory and implantation of the flickermeter in detail.

The flicker coefficient corresponds to continuous operation. However, in switching operations, two aspects are taken into account relating flicker emission. The first is the Flicker step factor which is a standardised measurement of the flicker emission caused by a single wind turbine switching operation, while the second is the Voltage change factor which measures the change in voltage during the switching operation. Switching operation cases occur when starting up the wind turbine in cut-in and rated wind speeds.

$k_{f}\left(\Psi_{k}\right)=\frac{1}{130} \frac{s_{k}}{s_{n}} P_{s t} T_{p}^{0.31}$

$k_{u}\left(\Psi_{k}\right)=\sqrt{3} \frac{U_{\max }-U_{\min }}{U_{n}} \frac{s_{k}}{S_{n}}$

Where $k_{f}\left(\Psi_{k}\right)$ is Flicker step factor, $k_{u}\left(\Psi_{k}\right)$ is Voltage change factor, $U_{\max }$ and $U_{\min }$ are maximum and minimum R.M.S voltage caused by a switching operation, and $U_{n}$ is the nominal Line to Line voltage.

According to [3], the Flicker coefficient, Flicker step factor and voltage change factor have to be given specified values of the network impedance phase angle $\left(30^{\circ}, 50^{\circ}, 70^{\circ}\right.$ and $\left.85^{\circ}\right)$ and the annual average wind speed $(6 \mathrm{~m} / \mathrm{s}, 7.5 \mathrm{~m} / \mathrm{s}, 8.5 \mathrm{~m} / \mathrm{s}$ and $10 \mathrm{~m} / \mathrm{s}$ ).

\section{B. Current Harmonics}

Wind turbines equipped with power electronic converters inject current harmonics which may contribute to the harmonic distortion of the voltage waveform. Thus, the Harmonic currents should be limited to a level that does not distort the voltage outside the required limits. To keep the current Harmonics within an acceptable limit, a filter is placed between the wind turbine converter and the grid [3][12]. The Fast Fourier Transformer (FFT) algorithm is adopted and developed in PSCAD/EMTDC to analyse and calculate the Harmonics magnitude and order.

\section{Voltage Dips}

A voltage dip is a quick decrease in the voltage for a time period between $1 \mathrm{~ms}$ to $1 \mathrm{~min}$. The value of decrement is up to $90 \%$ of nominal voltage. Voltage dips are caused by switching loads, starting up the wind turbine and faults which make larger dips [3][16]. The voltage dip of a wind turbine is defined by equation (16).

$d_{p}=100 k_{u}\left(\Psi_{k}\right) \frac{s_{n}}{s_{k}}$

\section{CASE StUdy AND Simulation PERFORMANCE}

The case study refers to wind energy conversion systems consisting of a wind turbine, a PMSG generator, an AC/DC IGBT-PWM back to back converter, an L filter and a radial distribution system. The wind turbine and PMSG data are given in table (I), whereas table (II) shows the converter parameter. The proposed system is designed and implemented using PSCAD/EMTDC software to analyse the dynamic behaviors of a wind turbine during varying wind speed. Figure 8 shows that wind turbines operate at maximum power point during varying wind speed. To investigate the contributions of PMSG-WT to the power quality, a radial distribution feeder consists of an ideal voltage source, grid impedance and a total load of 5.3 MVA (3.3 linear and 2 nonlinear loads) is connected to the WT system. Firstly, the 
load is isolated from the distribution feeder to investigate the contribution of the wind turbine to Flicker in the network.

\section{A. FLICKER}

The Flicker coefficient $C\left(\Psi_{k}, V_{a}\right)$ measures values for different values of different network impedance angles and annual average wind speed which are depicted in Table (III). Table (IV) illustrates the values of the Flicker step factor, the voltage change factor and voltage dip for switching operations and $\Psi_{k}=\left(70^{0}\right)$.

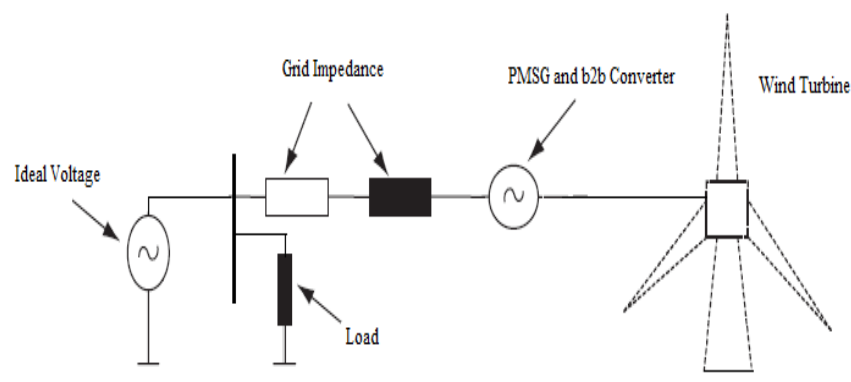

Fig. 8. Simulation model for voltage Flicker

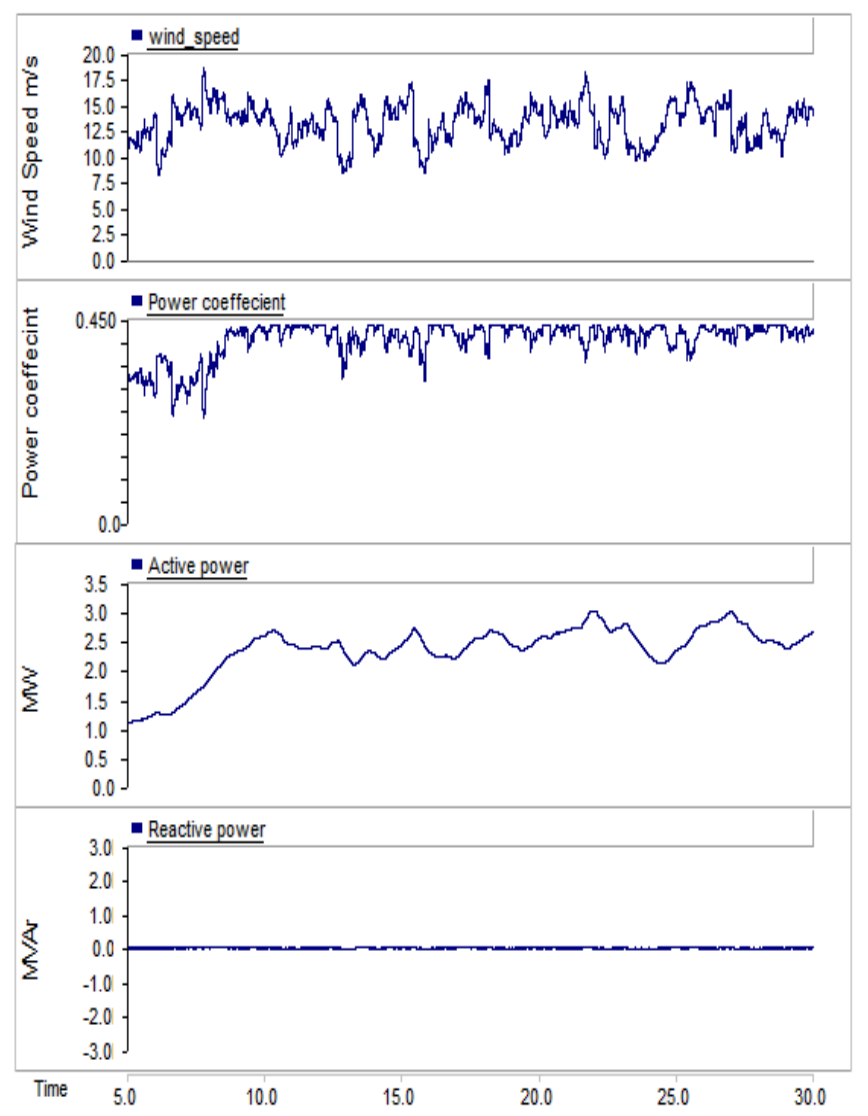

Fig. 9. Wind speed, Power coefficient, Active power and Reactive power
TABLE I

TYPE SIZES FOR CAMERA-READY PAPERS

\begin{tabular}{|c|c|}
\hline Wind turbine rated power (MW) & 3 \\
\hline Rotor diameter (m) & 41 \\
\hline Rotating speed (r.p.m) & 19 \\
\hline Nominal wind speed (m/s) & 13 \\
\hline Generator rated power (MW) & 3 \\
\hline Line to line voltage (V) & 690 \\
\hline Rated frequency (Hz) & 33 \\
\hline Pole pair number & 100 \\
\hline Stator resistance (p.u.) & 0.017 \\
\hline Unsaturated Xd (p.u.) & 0.5 \\
\hline Unsaturated Xq (p.u.) & 0.5 \\
\hline $\begin{array}{c}\text { Wind turbine and generator } \\
\text { inertia (p.u) }\end{array}$ & 4.654 \\
\hline Shaft damping (p.u.) & 0.02 \\
\hline
\end{tabular}

TABLE II

CONVERTER PARAMETERS

\begin{tabular}{|c|c|}
\hline DC-Link Voltage & 1500 \\
\hline DC-Capacitor $(\mu \mathrm{F})$ & 7800 \\
\hline Convert Switching Frequency $(\mathrm{HZ})$ & 4000 \\
\hline L Filter Inductance $(\mathrm{mH})$ & 0.132 \\
\hline
\end{tabular}

TABLE (III)

Flicker Coefficients for Different Wind Speed and Grid Angles

\begin{tabular}{|c|c|c|c|c|}
\hline \multirow{2}{*}{$\begin{array}{c}\text { Annual wind } \\
\text { speed }[\mathrm{m} / \mathrm{s}]\end{array}$} & \multicolumn{4}{|c|}{ Grid Impedance } \\
\cline { 2 - 5 } & $30^{0}$ & $50^{0}$ & $70^{0}$ & $85^{0}$ \\
\hline 6 & 0.16 & 0.201 & 0.236 & 0.26 \\
\hline 7.5 & 0.147 & 0.155 & 0.163 & 0.244 \\
\hline 8.5 & 0.145 & 0.16 & 0.173 & 0.238 \\
\hline 10 & 0.665 & 0.667 & 0.667 & 0.667 \\
\hline
\end{tabular}

Table (IV)

Flicker Step Factor, Voltage Change Factor and Voltage Dip for Switching Operations with Grid Impedance of $70^{\circ}$

\begin{tabular}{|c|c|c|}
\hline & Start up at cut-in speed & Start up at rated speed \\
\hline $\begin{array}{c}\text { Flicker step } \\
\text { factor }\end{array}$ & 0.251 & 0.326 \\
\hline $\begin{array}{c}\text { Voltage } \\
\text { change factor }\end{array}$ & 1.4 & 1.45 \\
\hline Voltage Dip \% & 21.75 & 21.87 \\
\hline
\end{tabular}

\section{B. HARMONICS}

The individuals and total harmonicas are measured with FFT devolved in PSCAD. First, a linear 3MVA load was connected, then a $0.6 \mathrm{MW}$ motorised and a nonlinear 2MVA were added to the feeder. The result referred to the distributing of current and voltage Harmonics. Obviously, it appears that the connections of nonlinear loads causes distortion to the voltage waveform and generates high Harmonics.

According to EN 50160 standards, the THD must not exceed $8 \%$. The simulation results are shown in Figures 10-12. Table (V) points out the magnitude of the odd order of the voltage Harmonics and total Harmonics distortion is shown in Table (VL). 


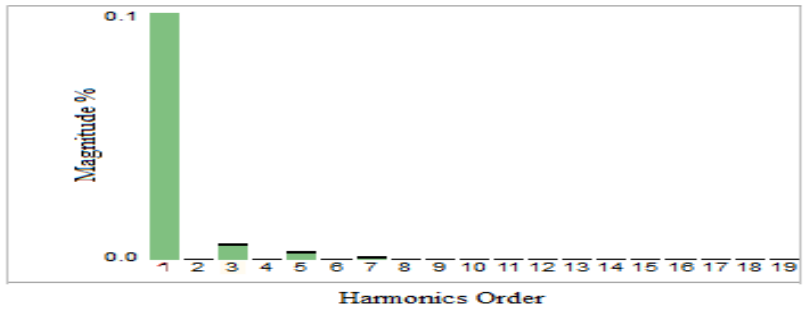

Fig. 10. Current Harmonics with Nonlinear Load

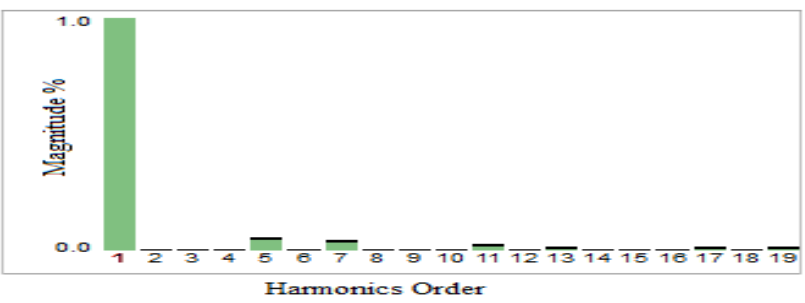

Fig. 11. Voltage harmonics with Linear Load

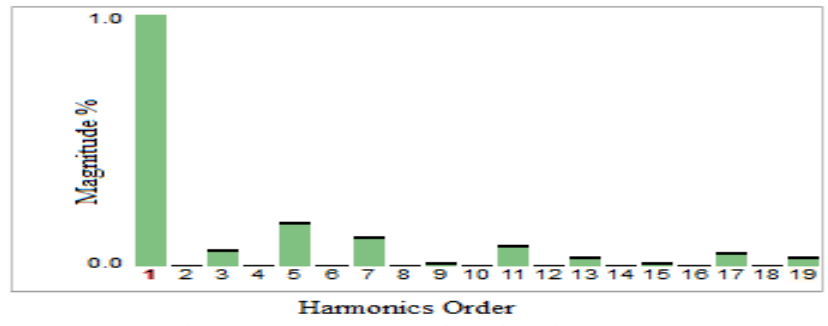

Fig. 12. Voltage harmonics with Linear Load

TABLE (V)

CURRENT AND VOLTAGE HARMONICS

\begin{tabular}{|c|c|c|c|c|c|c|c|c|c|}
\hline $\begin{array}{c}\text { Harmonics } \\
\text { order }\end{array}$ & $3 \mathrm{~d}$ & 5 th & 7 th & 9 th & 11 th & 13 th & 15 th & 17 th & 19 th \\
\hline $\begin{array}{c}\text { Current } \\
\text { with } \\
\text { nonlinear } \\
\text { Load }\end{array}$ & 0.56 & 0.2 & 0.1 & 0.01 & 0.04 & - & - & - & - \\
\hline $\begin{array}{c}\text { Voltage } \\
\text { with } \\
\text { nonlinear } \\
\text { Load }\end{array}$ & 0.3 & 5 & 3.7 & 0.2 & 1.6 & 0.13 & 0.1 & 0.9 & 0.71 \\
\hline $\begin{array}{c}\text { Voltage } \\
\text { with } \\
\text { nonlinear } \\
\text { Load }\end{array}$ & 6.1 & 17 & 11 & 0.7 & 7.4 & 3.1 & 0.5 & 4.6 & 2.5 \\
\hline
\end{tabular}

TABLE (VL)

CURRENT AND Voltage TOTAL HARMONiCS Distortion

\begin{tabular}{|c|c|}
\hline & THD\% \\
\hline Current with nonlinear Load & 4.2 \\
\hline Voltage without nonlinear Load & 1 \\
\hline Voltage with nonlinear Load & 3.3 \\
\hline
\end{tabular}

\section{CONCLUSION}

This paper presented a complete model of the variable speed wind turbine decoupled directly to a PMSG that is connected to an AC network via a full-scale converter. The complete system consists of a pitch-angled controlled wind turbine model, $3 \mathrm{p}$ oscillation Power, a drive train model and a PMSG model. In addition, a dq-synchronous rotating reference frame is built based on the dynamic model of the wind turbine with PMSG is designed to control both converter sides and to achieve the MPPT operation. The whole system was implemented in PSCAD/EMTDC software to investigate the impact of variable speed PMSG-WT on power quality. The wind turbine was connected to a grid with SCR of 20 MVA with a different impedance angle to measure the voltage stability, then a linear and a nonlinear load are injected into the grid to examine the harmonics, in view of this, variable speed PMSG-WT produces current Harmonics which lead to voltage harmonics in the connected grid, which is also due to $3 p$ oscillations and power fluctuation caused by wind variation. In addition, electrical Flicker is emitted to the utility grid.

\section{References}

[1] Rolan, Alejandro, et al. "Modeling of a variable speed wind turbine with a permanent magnet synchronous generator." Industrial Electronics, 2009. ISIE 2009.

[2] Lang, Yongqiang, Navid Zargari, and Samir Kouro. Power conversion and control of wind energy systems. Vol. 74. John Wiley \& Sons, 2011.

[3] Ackermann, Thomas, ed. Wind power in power systems. Vol. 140. Chichester, UK: John Wiley, 2005.

[4] Larsson, Ake. "Flicker emission of wind turbines during continuous operation."IEEE transactions on Energy Conversion 17.1 (2002): 114 118.

[5] Sun, Tao, Zhe Chen, and Frede Blaabjerg. "Flicker study on variable speed wind turbines with doubly fed induction generators." Energy Conversion, IEEE Transactions on 20.4 (2005): 896-905.

[6] Wu, Ziping, et al. "Comprehensive modeling and analysis of Permanent Magnet Synchronous Generator-Wind Turbine system with enhanced Low Voltage Ride Through Capability." Energy Conversion Congress and Exposition (ECCE), 2012 IEEE. IEEE, 2012.

[7] Yin, Ming, et al. "Modeling of the wind turbine with a permanent magnet synchronous generator for integration." Power Engineering Society General Meeting, 2007. IEEE. IEEE, 2007.

[8] Dolan, Dale, and P. W. Lehn. Real-time wind turbine emulator suitable for power quality and dynamic control studies. University of Toronto, 2005.

[9] Dolan, Dale SL, and Peter W. Lehn. "Simulation model of wind turbine $3 p$ torque oscillations due to wind shear and tower shadow." Power Systems Conference and Exposition, 2006. PSCE'06. 2006 IEEE PES. IEEE, 2006.

[10] Qiao, Wei, Xu Yang, and Xiang Gong. "Wind speed and rotor position sensorless control for direct-drive PMG wind turbines." Industry Applications, IEEE Transactions on 48.1 (2012): 3-11.

[11] Hsieh, Guan-Chyun, and James C. Hung. "Phase-locked loop techniques. A survey." Industrial Electronics, IEEE Transactions on 43.6 (1996): 609-615.

[12] Teodorescu, Remus, Marco Liserre, and Pedro Rodriguez. Grid converters for photovoltaic and wind power systems. Vol. 29. John Wiley \& Sons, 2011.

[13] Zhang, Jie, et al. "Power quality measurement and analysis of offshore wind farm based on PSCAD/EMTDC models." Advanced Computational Intelligence (ICACI), 2013 Sixth International Conference on. IEEE, 2013.

[14] Ruiz, Jesus, et al. "A precise analysis of the IEC flickermeter when subject to rectangular voltage fluctuations." Instrumentation and Measurement, IEEE Transactions on 58.11 (2009): 3839-3846.

[15] ] Cai, Rong. "Flicker interaction studies and flickermeter improvement." $\mathrm{PhD}$ research (2009).

[16] Jung, Hee-yeol, et al. "Power quality enhancement of grid-connected wind power generation system by SMES." Power Systems Conference and Exposition, 2009. PSCE'09. IEEE/PES. IEEE, 2009. 